\title{
Objective and subjective results of the Bonebridge transcutaneous active direct-drive bone conduction hearing implant
}

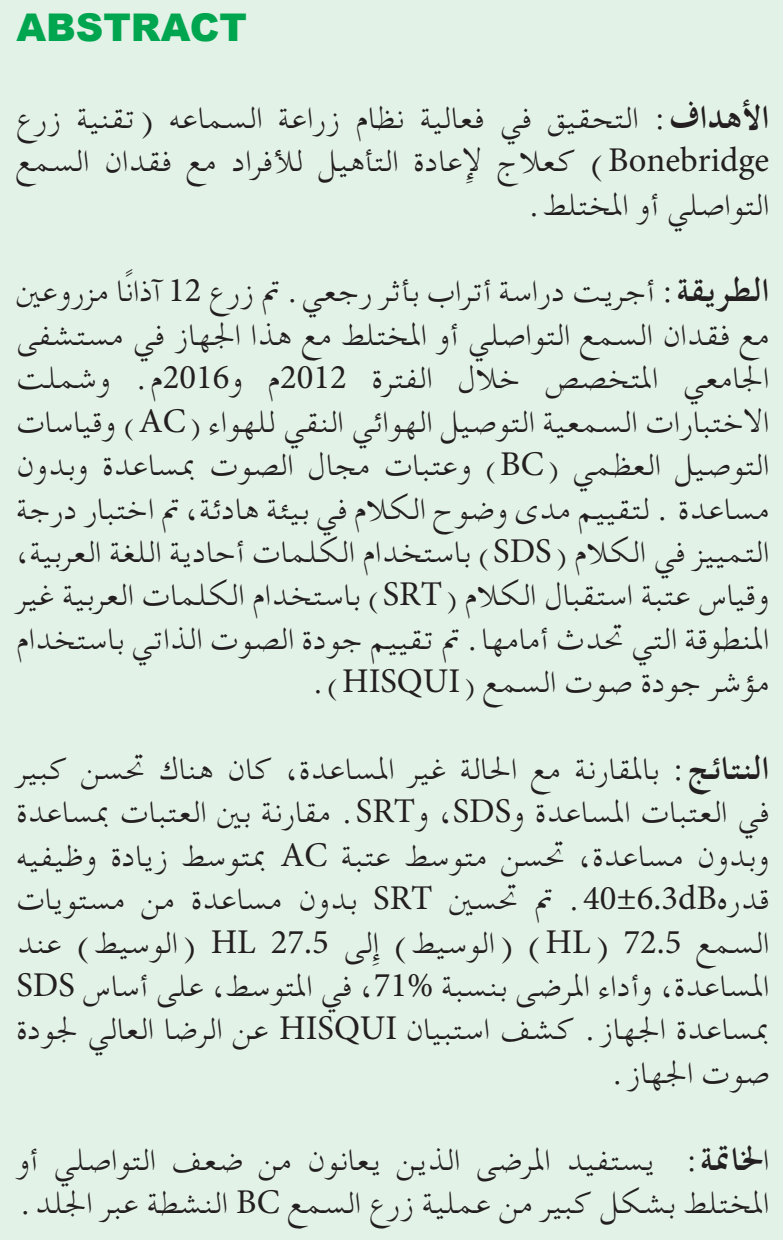

Objectives: To investigate the effectiveness of a boneanchored hearing implant system (Bonebridge implant technology) as a rehabilitation treatment for individuals with conductive or mixed hearing losses.

Methods: This is a retrospective cohort study. Twelve implanted ears with conductive or mixed hearing losses were implanted with this device at a tertiary university hospital between 2012 and 2016. Audiological tests included pure tone air conduction $(\mathrm{AC})$ and bone conduction (BC) measurements and unaided and aided sound-field thresholds. Toevaluate thespeechintelligibility in a quiet environment, the speech discrimination score (SDS) was tested using Arabic monosyllabic words, and the speech reception threshold (SRT) was measured using Arabic disyllabic words spoken in front of them. The subjective sound quality was assessed with the Hearing Implant Sound Quality Index (HISQUI).

Results: In comparison with the unaided condition, there was a significant improvement in the aided thresholds, SDS, and SRT. Comparing the aided and unaided thresholds, the average AC threshold improved with an average functional gain of $40 \pm 6.3 \mathrm{~dB}$. The unaided SRT improved from $72.5 \mathrm{~dB}$ hearing levels (HL)(median) to $27.5 \mathrm{~dB} \mathrm{HL}$ (median) when aided, and patients performed $71 \%$ better, on average, based on the SDS with the help of the device. The HISQUI questionnaire revealed high satisfaction with the device sound quality.

Conclusion: Patients with conductive and mixed hearing loss substantially benefit from the Bonebridge active transcutaneous $\mathrm{BC}$ hearing implant.

Saudi Med J 2019; Vol. 40 (8): 797-801

doi: $10.15537 /$ smj.2019.8.24383

From the King Abdullah Ear Specialist Center, College of Medicine, King Saud University, Riyadh, Kingdom of Saudi Arabia.

Received 28th March 2019. Accepted 8th July 2019.

Address correspondence and reprint request to: Dr. Farid Alzhrani, King Abdullah Ear Specialist Center, College of Medicine, King Saud University, Riyadh, Kingdom of Saudi Arabia. E-mail: Faz1420@hotmail.com ORCID ID: https://orcid.org/0000-0002-0564-7204 
T The air conduction (AC) pathway is modified, restricted, or completely lost in patients with conductive or mixed hearing loss. Although defects of the tympanic membrane and the ossicular chain can be treated to a certain extent by surgery, adequate hearing restoration is not achieved in some cases even with the addition of conventional hearing aids. Active bone conduction (BC) implants can be beneficial to these patients as $\mathrm{BC}$ transmission of the acoustic signal bypasses the normal AC pathway. ${ }^{1}$ Consequently, BC hearing implants have become a mainstream treatment for conductive, mixed, or single-sided hearing loss that does not benefit from conventional hearing aids. ${ }^{2}$ Attempts to effectively restore hearing in these patients have included surgical implantation of percutaneous BC implants. Although effective, safe, and well-established in the market, they were associated with a significant number of post-operative complications leading to revision surgery. ${ }^{3}$ In an extensive series of patients $(\mathrm{n}=602)$ over a 20 -year period, Hobson et $\mathrm{al}^{4}$ reported a complication rate of $24 \%$ and a revision surgery rate of $12 \%$. Therefore, the transcutaneous $\mathrm{BC}$ implants were introduced to minimize the complication rate.

The Bonebridge System (BB, Med-El Corporation, Innsbruck, Austria), is one of these transcutaneous bone conduction hearing implants. It is an intact skin semi-implantable hearing system consisting of 2 components: the external audio processor and the internal implantable part known as the $\mathrm{BC}$ implant. The transcutaneous $\mathrm{BC}$ implants including $\mathrm{BB}$ avoids drawbacks associated with percutaneous implants such as skin reactions, the growth of skin over the abutment, implant extrusions, wound infections, and fixture losses. Therefore, it is reported that, the complication rate is higher in percutaneous $\mathrm{BC}$ implant in comparison with transcutaneous one. ${ }^{5}$ As the $\mathrm{BC}$-implant is secured to bone by screws, the osseointegration process is not required and the device may be activated within 2 or 3 weeks after it is implanted.

It is reported that, the performance of active transcutaneous bone conduction hearing implant is also superior to the passive skin-drive BC devices with implanted magnets that are subjected to atranscutaneous signal attenuation of 10 to $15 \mathrm{~dB},{ }^{6}$ because in active transcutaneous $\mathrm{BC}$ implant the signal is independent from the thickness of the skin and hair.

Disclosure. Authors have no conflict of interests, and the work was not supported or funded by any drug company.
The purpose of the present study was to evaluate the audiological outcome as well as the speech benefit of the BB implanted patients in our center.

Methods. After approval by the Institutional Review Board of King Saud University, College of Medicine, Riyadh, Saudi Arabia data were retrospectively compiled for this study. We reviewed hospital charts of 12 implanted ears that received BB implantations at our university hospital (tertiary referral center) between July 2012 and February 2016. All implanted patients during that period have been included. The incomplete file was our exclusion criteria. Data regarding the general demographics as well as the cause of deafness, onset and duration of deafness, number of patients who had minor or major complications, or those who required revision were collected.

Prior to implantation, pure tone $\mathrm{AC}$ and $\mathrm{BC}$ thresholds were obtained in both the unaided and aided conditions. When calculating the puretone average (PTA4), the $0.5,1,2$, and $4 \mathrm{kHz}$ thresholds were utilized. The functional gain was calculated as the difference between the mean PTA4AC and aided PTA4.

To evaluate the speech intelligibility, the speech discrimination score (SDS) was tested using Arabic monosyllabic words; speech stimuli were presented at $65 \mathrm{~dB}$ hearing level (HL) in a quiet environment. The speech reception threshold (SRT) was measured using Arabic disyllabicwords (50\% correct) with speech and the noise signal arriving from the front. All hearing tests were performed monaurally, where the contralateral side plugged and masked while testing the implanted ear.

The Hearing Implant Sound Quality Index (HISQUI) questionnaire was used to evaluate the subjective sound quality of the $\mathrm{BB}$. The questionnaire consists of 29 questions with 7 possible answers each, ranging from "never" to "always". An example question is: "Can you effortlessly distinguish between a male and a female voice?" Each answer has a value between 1 and 7, those values are totaled to obtain the HISQUI score. The HISQUI score corresponds to one of 5 categories between poor and very good sound quality.

Post-operative BB-aided thresholds and audiological data obtained in one-year follow-up visits were compared to the preoperative results. Due to the low number of data points, a normal distribution of the data could not be confirmed. The non-parametric Wilcoxon test was performed to test for significance between groups and the software STATISTICA 12 was used. Graphs were created using GraphPad Prism 7.02. 
Results. The individual demographic and clinical data for 12 implanted ears are shown in Table 1. In 9 ears, the BC-FMT was placed in the sinodural angle and in 3 ears the BC-FMT had to be placed using a retrosigmoid approach. No intraoperative, minor, or major postoperative complications were observed. There was no incidence of revision surgery in any of the patients.

Pure tone audiometry. We compared the pre- and post-operative BC thresholds (PTA4BC) to assess the safety of the surgical procedure. The difference was not larger than $5 \mathrm{~dB}$ for any patient; thus, all were within the accuracy interval of the $\mathrm{BC}$ measurement $( \pm 5 \mathrm{~dB})$ (Figure 1).

Across all frequencies, aided sound field (SF) thresholds were significantly improved by the BB. The mean aided PTA4SF was 29.8dB HL compared with the mean unaided PTA 4 SF of $74.6 \mathrm{~dB}$ HL. The average functional gain was $40 \pm 6.3 \mathrm{~dB}$ HL (Figure 2).

Speech audiometry. The hearing ability in a quiet environment also significantly improved. The SRT with $\mathrm{BB}$ was lower in all patients compared to the preoperative SRT. The mean pre-operative SRT decreased from $67.8 \mathrm{~dB}$ HL (SD 18.5 dB HL) to $27.9 \mathrm{~dB} \mathrm{HL}$ (SD $5.6 \mathrm{~dB} \mathrm{HL}$ ) (Figure 3).

Table 1 - Demographic and clinical data of 12 implanted ears.

\begin{tabular}{|c|c|c|c|c|c|}
\hline $\begin{array}{l}\text { Implanted } \\
\text { ear }\end{array}$ & Side & $\begin{array}{l}\text { Air-bone } \\
\text { gap }\end{array}$ & $\begin{array}{l}\text { Age at } \\
\text { surgery } \\
\text { (years) }\end{array}$ & $\begin{array}{l}\text { Surgical } \\
\text { indication }\end{array}$ & $\begin{array}{l}\text { Surgical } \\
\text { approach }\end{array}$ \\
\hline A & Left & 29 & 24 & Bilateral CHL & BB left \\
\hline B & Right & 33 & 24 & Bilateral CHL & $\mathrm{BB}$ right \\
\hline C & Left & 60 & 22 & Bilateral microtia & $\begin{array}{c}\text { BB left, } \\
\text { BAHA right }\end{array}$ \\
\hline $\mathrm{D}$ & Right & 54 & 28 & Bilateral microtia & BB right \\
\hline $\mathrm{E}$ & Left & 59 & 28 & Bilateral microtia & BB left \\
\hline $\mathrm{F}$ & Right & 60 & 23 & Bilateral microtia & $\begin{array}{l}\text { BB right, } \\
\text { BAHA left }\end{array}$ \\
\hline G & Left & 54 & 46 & $\begin{array}{l}\text { MHL left, } \\
\text { Normal hearing } \\
\text { right }\end{array}$ & BB left \\
\hline $\mathrm{H}$ & Left & 56 & 33 & $\begin{array}{l}\text { Microtia left, } \\
\text { Normal hearing } \\
\text { right }\end{array}$ & BB left \\
\hline I & Left & 39 & 21 & Bilateral CHL & BB left \\
\hline $\mathrm{J}$ & Left & 48 & 13 & Bilateral CHL & BB left \\
\hline K & Left & 40 & 57 & $\begin{array}{l}\text { MHL left, } \\
\text { Normal hearing } \\
\text { right }\end{array}$ & BB left \\
\hline $\mathrm{L}$ & Right & 60 & 8 & Right Microtia & $\mathrm{BB}$ right \\
\hline Mean & & 49 & 27 & & \\
\hline SD & & & 9 & & \\
\hline
\end{tabular}

Before implantation of the $\mathrm{BB}$, the mean SDS was $26.7 \%$ (SD 34\%) in the unaided condition. One year after implantation, the mean SDS was $90-100 \%$ for monosyllables at $65 \mathrm{~dB}$ sound pressure level (SPL) (mean: $97.1 \%$, SD 4.8\%). The improvement in sound discrimination was statistically significant $(p=0.0078)$ (Figure 4).

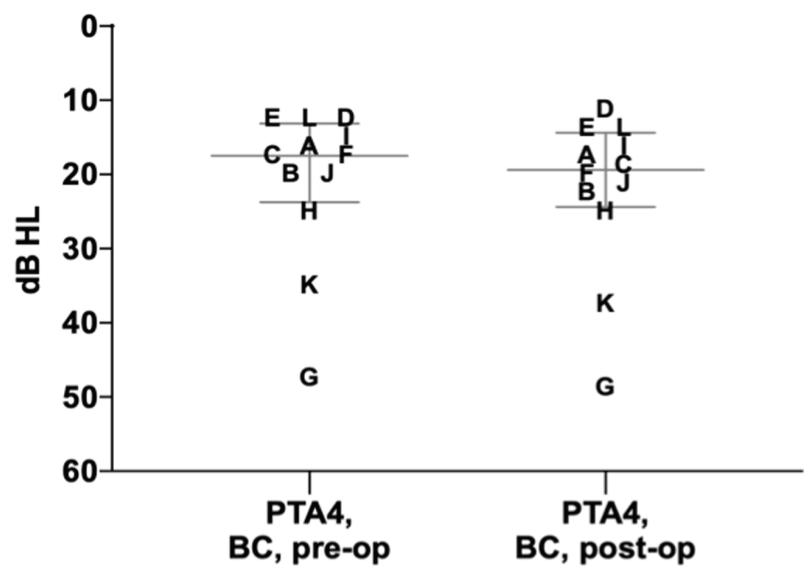

Figure 1 - A comparison of bone conduction (BC) thresholds as preoperation (pre-op) versus post-operation (post-op) puretone average (PTA4) values. The plot shows the individual data points and each letter represents a tested ear $(n=12)$ and the median (long line) with the interquartile range (25th and 75 th percentile, whiskers). The greatest difference between pre- and post-op BC PTA4 values is $2.5 \mathrm{~dB}$ hearing levels (HL) (ear $\mathrm{B}, \mathrm{F}$ and $\mathrm{K}$ ), which is within the retest variability of $5 \mathrm{~dB}$. Consistent with this trend, all frequency related post-op BC values differ less than $5 \mathrm{~dB}$ from the pre-op value.

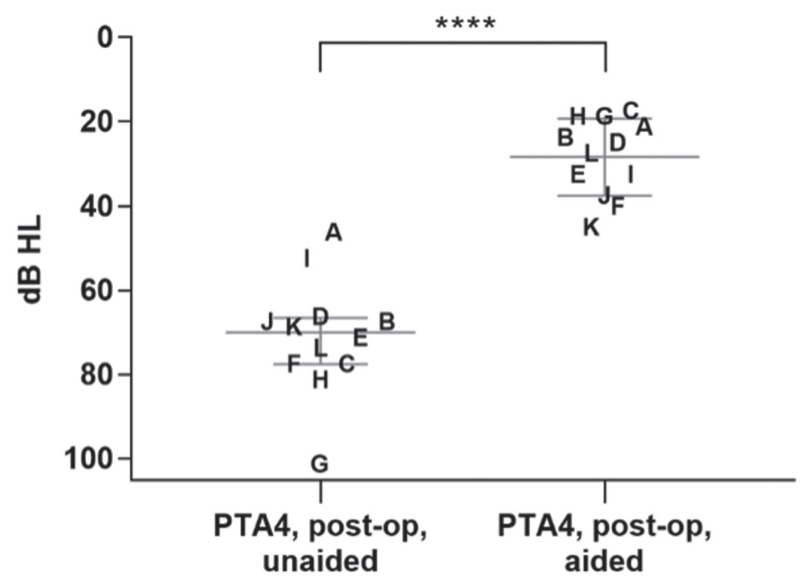

Figure 2 - A comparison of the post-operation (post-op) puretone average (PTA4) $(0.5,1,2$, and $4 \mathrm{kHz})$ unaided and aided with the Bonebridge implant. The scatter plot shows the individual data points where each letter represents a study participant and the median (long line) with the interquartile range (25th and 75th percentile, whiskers). The non-parametric Wilcoxon test was used to test for statistical significance $(p=0.0001$, $\mathrm{n}=12$ ). AC - air conduction, HL - hearing level. 


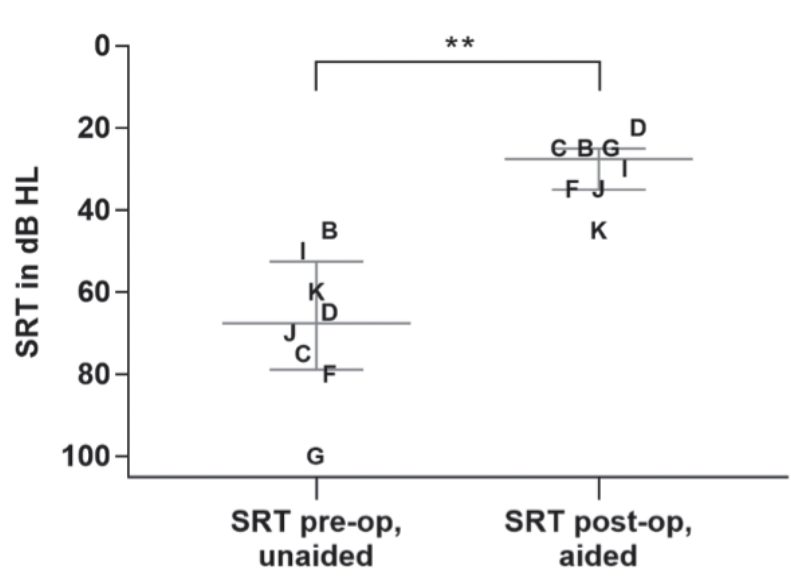

Figure 3 - A comparison of the pre-operation (pre-op) speech recognition threshold (SRT) in a quiet environment, unaided, with the aided values measured post-operatively (post-op). The speech material consisted of Arabic disyllabic words. The plot shows the individual data points where each letter represents a study participant and the median (long line) with the interquartile range (25th and 75th percentile, whiskers). The normal distributed $\mathrm{t}$ test was used to test for statistical significance $\left(p=0.001,{ }^{* *} p \leq 0.05, \mathrm{n}=8\right)$.

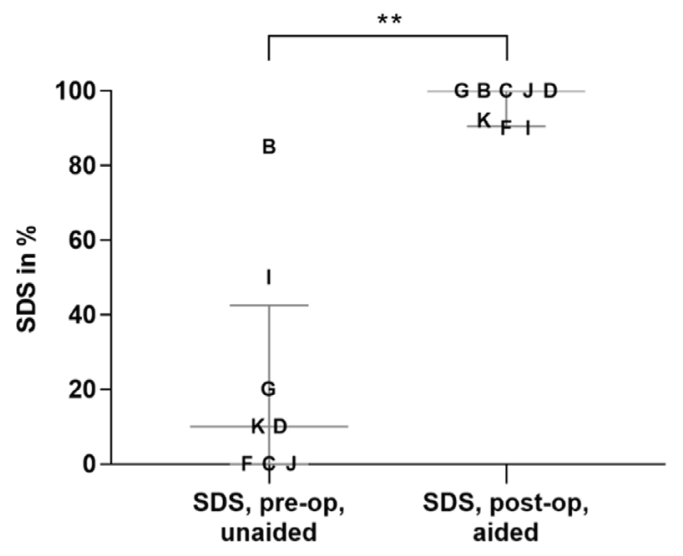

Figure 4 - A comparison of the unaided pre-operation (pre-op) speech discrimination score (SDS) versus the post-operation (post-op) score aided with the Bonebridge. The SDS was measured at $40 \mathrm{~dB}$ sensation levels (SL) (65 dB hearing levels (HL), Arabic monosyllabic words). The plot shows the individual data points where each letter represents a study participant and the median (long line) with the interquartile range (25th and 75 th percentile, whiskers). The median value of SDS pre-op was $10 \%$, whereas this value was $100 \%$ for post-op. The nonparametric Wilcoxon test was used to test for statistical significance $\left(p=0.0078,{ }^{* *} p \leq 0.05, \mathrm{n}=8\right)$.

Hearing Implant Sound Quality Index (HISQUI). The HISQUI questionnaire was used to evaluate the subjective sound quality of the BB. The total satisfaction of the participants regarding sound quality of the $\mathrm{BB}$ system was good. (Figure 5). Sixty-seven percent of the participants rated the improvement as good to very good.

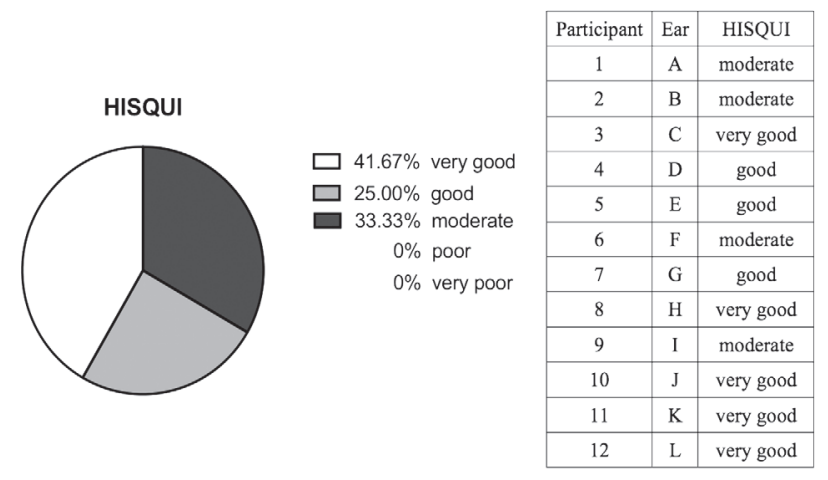

Figure 5 - The hearing implant sound quality index (HISQUI) questionnaire was used to evaluate the subjective sound quality of the Bonebridge $(n=12)$.

Discussion. This study demonstrates the clinical and subjective benefit of the $\mathrm{BB}$ in patients with conductive or mixed hearing losses. In agreement with other recent reports, ${ }^{7-9}$ we demonstrated that the $\mathrm{BB}$ implant procedure can be considered safe; also, there are clinical and subjective improvements of the hearing threshold in its users. Audiological results showed an improved ABG as well as PTA4, SRT, and SDS values with the BB. Similar to other studies, ${ }^{7,10}$ the post-operative $\mathrm{BC}$ thresholds remained stable in all the patients implying that their residual hearing was unaffected by the surgical procedure.

The functional gain observed in this analysis $(40 \pm 6.3 \mathrm{~dB})$ was slightly better than those reported by Ihler et $\mathrm{al}^{11}(33.6 \pm 7.2 \mathrm{~dB})$, Barbara et $\mathrm{al}^{12}(36.5 \mathrm{~dB})$, Manrique et $\mathrm{al},{ }^{8}$ and Hassepass et al. ${ }^{5}$ Similarly, another study conducted in $2013^{9}$ reported a mean functional gain of more than $20 \mathrm{~dB}$ across all frequencies $(0.5,1$, $2,4 \mathrm{kHz})$. However, Hougaard et $\mathrm{al}^{17}$ reported that the functional gain in conductive or mixed hearing loss patients by using BAHA attract was $19.8 \mathrm{~dB}$, which is much lower than the improvement reported by using $\mathrm{BB}$ implant. Also, in our study, a significant improvement was observed in speech recognition in a quiet environment; the improvement was on par with those reported by other researchers that used German monosyllabic word lists ${ }^{11}$ and by those that used disyllabic word lists in Spanish. ${ }^{8}$ In a quiet environment, the efficacy of the $\mathrm{BB}$ found in the present study $(97.1 \%$, SD $4.8 \%)$ was in the same range reported by other studies. Schmerber et $\mathrm{al}^{2}$ reported a follow-up period of one year, similar to the present study, and their participants achieved a mean speech recognition score of $95 \%$ (SD 15\%). Meanwhile, Sprinzl et al ${ }^{9}$ reported a mean monosyllabic word recognition score of $14.2 \%$ in pre-operative investigations that improved to $92.9 \%$ post-operatively. A similar improvement, 
$16.7 \%$ pre-operatively versus $80 \%$ post-operatively, was observed by Ihler et al. ${ }^{11}$ Manrique et al ${ }^{8}$ obtained a mean recognition score of $66.2 \%$ pre-operatively, improving to $86.2 \%$ post-operatively, using a disyllabic word list.

Percutaneous BC implants have been widely used in the treatment of hearing loss for a long time. However, the drawback of percutaneous implants is the risk of infection at the abutment. The intact skin above the $\mathrm{BB}$ implant decreases the rate of infection and places the $\mathrm{BB}$ in an advantageous position over the wellestablished percutaneous BC implants. Moreover, it will also help to reduce the stigmatization associated with implantation. Though the $\mathrm{BB}$ and the bone anchored hearing aid (BAHA), another hearing implant system, ${ }^{13}$ present comparable outcomes, the $\mathrm{BB}$ may be more appealing to patients.

Sprinzl et $\mathrm{al}^{9}$ demonstrated that $\mathrm{BB}$ implantation has a very low rate of minor adverse events $(5.12 \%)$ and revision surgery $(0.85 \%)$. In our study, after 2 years of $\mathrm{BB}$ use, no revision surgery and no skin reactions were reported, similar to short-term follow-up studies. ${ }^{2,5,8,9,11,14}$ Moreover, the $\mathrm{BB}$ has a much lower complication rate than the BAHA implant (24\%) that is associated with a higher rate of revision surgery $(12 \%) .{ }^{4}$ In the long-term follow-up (mean: 14 years) of BAHA use, the skin reaction rate $(31 \%)$, loss of osseointegration (17\%), and need for revision surgery (34\%) have been reported. ${ }^{15}$ The relatively large size of $\mathrm{BB}$ implant necessitates a good preoperative radiological evaluation of temporal bone, to examine if the patient has adequate place which could accommodate the implant. Laske et $\mathrm{al}^{16}$ measured the subjective satisfaction of 9 patients after BB implantation with 2 questionnaires (a modified version of the Speech, Spatial, and Qualities of Hearing questionnaire [SSQ-B] and the Bern Benefit in SingleSided Deafness Questionnaire [BBS]). Similar to their findings, the majority of our patients reported moderate improvements and 57\% rated the improvement as good to very good.

Study limitation. The sample size was a major limitation of the present study.

In conclusions, patients with conductive or mixed hearing losses substantially benefit from the BB active transcutaneous $\mathrm{BC}$ hearing implant without minor or major complications.

\section{References}

1. Cremers CW, O’Connor AF, Helms J, Roberson J, Clarós $\mathrm{P}$, Frenzel $\mathrm{H}$, et al. International consensus on Vibrant Soundbridge ${ }^{\varpi}$ implantation in children and adolescents. Int J Pediatr Otorhinolaryngol 2010; 74: 1267-1279.
2. Schmerber S, Deguine O, Marx M, Van de Heyning P, Sterkers $\mathrm{O}$, Mosnier I, et al. Safety and effectiveness of the Bonebridge transcutaneous active direct-drive bone-conduction hearing implant at 1-year device use. Eur Arch Otorbinolaryngol 2017; 274: 1835-1851.

3. Vyskocil E, Liepins R, Kaider A, Blineder M, Hamzavi S. Sound localization in patients with congenital unilateral conductive hearing loss with a transcutaneous bone conduction implant. Otol Neurotol 2017; 38: 318-324.

4. Hobson JC, Roper AJ, Andrew R, Rothera MP, Hill P, Green $\mathrm{KM}$. Complications of bone-anchored hearing aid implantation. J Laryngol Otol 2010; 124: 132-136.

5. Hassepass F, Bulla S, AschendorffA, Maier W, Traser L, Steinmetz $\mathrm{C}$, et al. TheBonebridgeas a transcutaneous bone conduction hearing system: preliminary surgical and audiological results in children and adolescents. Eur Arch Otorhinolaryngol 2015; 272: 2235-2241.

6. Mulla O, Agada F, Reilly PG. Introducing the Sophono Alpha 1 abutment free bone conduction hearing system. Clin Otolaryngol 2012; 37: 168-169.

7. Rahne T, Seiwerth I, Götze G, Heider C, Radetzki F, Herzog M, et al. Functional results after Bonebridge implantation in adults and children with conductive and mixed hearing loss. Eur Arch Otorhinolaryngol 2015; 272: 3263-3269.

8. Manrique M, Sanhueza I, Manrique R, de Abajo J. A new bone conduction implant: surgical technique and results. Otol Neurotol 2014; 35: 216-220.

9. Sprinzl G, Lenarz T, Ernst A, Hagen R, Wolf-Magele A, Mojallal H, et al. First European multicenter results with a new transcutaneous bone conduction hearing implant system: shorttermsafety and efficacy. Otol Neurotol 2013; 34: 10761083.

10. Baumgartner WD, Hamzavi JS, Böheim K, Wolf-Magele A, Schlögel M, Riechelmann $\mathrm{H}$, et al. A new transcutaneous bone conduction hearing implant: short-term safety and efficacy in children. Otol Neurotol 2016; 37: 713-720.

11. Ihler F, Volbers L, Blum J, Matthias C, Canis M. Preliminaryfunctional results and quality of life after implantation of a new bone conduction hearing device in patients with conductive and mixed hearing loss. Otol Neurotol 2014; 35: 211-215.

12. Barbara M, Perotti M, Gioia B, Volpini L, Monini S. Transcutaneous bone-conduction hearing device: audiological and surgical aspects in a first series of patients with mixed hearing loss. Acta Otolaryngol 2013; 133: 1058-1064.

13. Pfiffner F, Caversaccio M, Kompis M. Audiological results with Baha in conductive and mixed hearing loss. $A d v$ Otorhinolaryngol 2011; 71: 73-83.

14. Bianchin G, Bonali M, Russo M, Tribi L. Active bone conduction system: outcomes with the Bonebridge transcutaneous device. ORL J Otorhinolaryngol Relat Spec 2015; 77: 17-26.

15. Badran K, Bunstone D, Arya AK, Suryanarayanan R, Mackinnon N. Patient satisfaction with the bone-anchored hearing aid: a 14-year experience. Otol Neurotol 2006; 27: 659-666.

16. Laske RD, Röösli C, Pfiffner F, Veraguth D, Huber AM. Functional results and subjective benefit of a transcutaneous bone conduction device in patients with single-sided deafness. Otol Neurotol 2015; 36: 1151-1156.

17. Hougaard DD, Boldsen SK, Jensen AM, Hansen S, Thomassen PC. A multicenter study on objective and subjective benefits with a transcutaneous bone-anchored hearing aid device: first Nordic results. Eur Arch Otorhinolaryngol 2017; 274: 30113019 . 